REDES- Revista hispana para el análisis de redes sociales

Vol.21,\#8, Diciembre 2011

http://revista-redes.rediris.es

\title{
VennMaker para historiadores: fuentes, redes sociales y programas informáticos ${ }^{1}$
}

\author{
Marten Düring- Kulturwissenschaftliches Institut Essen (KWI), Alemania \\ Matthias Bixler- Department of History, University of Trier, Alemania \\ Michael Kronenwett- Department of Anthropology, University of Trier, Alemania \\ Martin Stark- Department of History, University of Trier², Alemania
}

\begin{abstract}
Resumen
Este artículo explora la aplicabilidad del programa informático VennMaker para la investigación histórica. El artículo se apoya en dos casos de estudio de investigaciones históricas actuales orientadas a estudiar las redes y que cubren diferentes periodos de tiempo y distintas fuentes. La mayor ventaja de VennMaker es que invierte el proceso de recolección de datos. Mientras que los programas tradicionales utilizan datos pre-codificados para producir el mapa de una red, VennMaker genera los datos mientras que el investigador dibuja los nodos y crea el mapa de una red. Las bases de datos de matrices prefabricadas ya no son necesarias; por lo tanto, el programa puede ser utilizado fácilmente por historiadores que no se han formado en las ciencias sociales. Los dos casos incluyen el análisis de una estructura familiar en la historia antigua y las redes egocentradas de judíos que se escondían durante el Nacional-Socialismo. Artumentamos que una representación visual de las relaciones sociales ayuda a revelar modelos invisibles y caracerísticas de las redes que ofrecen a los investigadores nuevas perspectivas sobre sus temas de investigación. El programa ofrece una variedad de herramientas para representar las relaciones sociales y su desarrollo a lo largo del tiempo y del espacio.
\end{abstract}

Palabras clave: Visualización - Programas informáticos - Recolección de datos Historia antigua.

\begin{abstract}
This paper explores the applicability of the software VennMaker to historical research. The paper draws on two case studies from current network-oriented historical research projects, covering different time periods and sources. VennMaker's biggest advantage is that it inverts the process of data collection. While traditional software uses pre-coded data to produce a network map, VennMaker generates data while the researcher draws nodes and creates a network map. Prefabricated data matrices are no longer necessary; therefore, the software can easily be used by historians lacking training in the social sciences. Our two cases include an analysis of a family structure in ancient history and ego-networks of Jews in hiding during National Socialism. We argue that a visual representation of social relations helps to reveal unseen patterns and characteristics of networks therefore offering scholars new perspectives on their research subjects. The software offers a variety of tools to represent social relations and their development over time and space.
\end{abstract}

Key words: Visualization - Software - Data collection - Ancient History Contemporary History

\footnotetext{
${ }^{1}$ Artículo traducido por Ainhoa de Federico y Lola de la Rúa.

2 Información de contacto: Marten Düring martenduering@googlemail.com, Matthias Bixler bixl3201@uni-trier.de, Michael Kronenwett kronenwe@uni-trier.de, Martin Stark martinstark1@gmx.de.
} 


\section{Introducción}

En las últimas décadas, varios estudios en las ciencias sociales han mostrado que los métodos formales derivados del análisis de redes sociales pueden ser aplicados a corpus seleccionados de datos históricos. Estos estudios, sin embargo, tienden a estar fuertemente influidos por los estándares de procesado de datos y, por encima de todo, de los paradigmas epistemológicos que tienen sus raices en las ciencias sociales (por ejempo: Barkey y Rossem, 1997; Brudner y White, 1997; Padgett y Ansell, 1993; Windolf, 2007). Desde el punto de vista de un historiador, los científicos sociales historiadores que llevan a cabo estos estudios no tuvieron en cuenta, en la mayoría de los casos, de forma adecuada, los límites de las fuentes históricas y su naturaleza frecuentemente fragmentaria y contradictoria cuando son usados para extraer datos relacionales (una rara excepción: Franzosi, 1996).

Sin embargo los historiadores han están formados especialmente para considerar los límites de sus fuentes. Toda su educación profesional está dirigida a manejar información sensible sobre el pasado. Para hacerlo, utilizan una tríada metodológica consistente en la heurística, la crítica de las fuentes y la interpretación de las fuentes. Un efecto secundario de esta concentración necesaria en el método histórico como base de toda la investigación histórica es que, en la mayoría de los casos, los historiadores no reciben una formación adecuada en los métodos formales socio-científicos. Si a eso se le añade la escasez de fuentes, todo ello ha obstaculizado la aplicación comprehensiva, válida y significativa de los métodos provenientes del análisis de redes sociales durante cierto tiempo. En la mayoría de los casos el término red sólo ha sido utilizado de forma metafórica en la investigación histórica, pero durante la última década cada vez más historiadores se han enfrentado a los desafíos abiertos por el análisis de redes sociales (véase por ejemplo: Boyer, 2008; Düring y Keyserlingk, forthcoming; Düring y Stark, 2011; Gorißen, 2006; Neurath y Krempel, 2008; Reitmayer y Marx, 2010). ${ }^{3}$ Sin embargo sigue habiendo cuestiones metodológicas respecto al uso comprensivo del análisis de redes formal en los proyectos de investigación histórica orientados por las redes. Algunos de dichos proyectos utilizan meramente las características formales del análisis de redes para la exploración visual de datos históricos (véase: Grommes, 2008; Krempel y Lipp, 2001; Reupke y Volk, en prensa; Stuber et al., 2008). Los programas informáticos disponibles para analizar y visualizar las redes sociales

3 Para una bibliografía extensiva sobre el análisis de redes históricas véase: https://sites.google.com/site/historicalnetworkresearch (acceso el 8 de noviembre 2011). 
procesan típicamente matrices prefabricadas, las cuales, a su vez, requieren una cantidad considerable de conocimientos, tiempo y recursos humanos para codificar, ajustar e interpretar. Por lo tanto frecuentemente se hace difícil decidir si un esfuerzo y un tiempo adicionales merecerán la pena en términos de descubrimientos valiosos.

Un equipo interdisciplinario basado en un grupo de investigación sobre redes sociales en las universidades de Tirer y Mainz ${ }^{4}$ ha producido VennMaker, programa cuyo objetivo es simplificar y agilizar el proceso de codificación visualización y análisis de las redes sociales. Mientras que los programas tradicionales requieren que los usuarios introduzcan los datos relacionales en bases de datos antes de poder producir una visualización de la red, VennMaker genera dichos datos mientras el investigador dibuja los nodos y crea un mapa de la red. Las matrices de datos prefabricadas ya no son, por lo tanto, necesarias. De este modo, el programa invierte el proceso de recolección de datos y puede ser utilizado fácilmente por historiadores y otros investigadores sin formación en ciencias sociales.

El objetivo de este artículo es demostrar las capacidades de VennMaker para la investigación histórica. Como herramienta heurística para la exploración visual de las redes tiene el potencial de generar nuevos temas de investigación o reinvestigar temas antiguos al proveer al investigador de una visión relacional de su campo. En segundo lugar, el artículo presenta dos aproximaciones a la investigación de las redes históricas. El primer caso de estudio, sobre un conflicto entre una familia Augusta a finales del siglo primero AC, ejemplifica cómo se podría utilizar el análisis de redes sociales formales en la historia Antigua para explorar el potencial que las estructuras sociales tienen para afectar los actos de los individuos. Esta aproximación estructural ayuda a reconsiderar y poner a prueba resultados anteriores que no pueden ser recogidos directamente de las fuentes. El segundo caso de estudio examina relatos autobiográficos de judíos durante el Tercer Reich y provee una comparación estructurada de sus redes personales. Este área de la historia contemporánea es suficientemente rica en fuentes para proveer de información para reconstruir las redes correspondientes.

Dichas redes son modelos simplificados de realidades sociales pasadas que, a su vez, dependen de nuestra interpretación de las fuentes históricas. Cualquier análisis

\footnotetext{
${ }^{4}$ Se puede encontrar más información sobre el grupo de excelencia "Gesellschaftliche Abhängigkeiten und soziale Netzwerke" en las Universidades de Trier y Mainz en www.netzwerk-exzellenz.uni-trier.de (acceso el 30 de noviembre 2011).
} 
formal de las redes históricas implica una reducción sistemática de la información, en contraste con las reconstrucciones detalladas utilizadas típicamente en las investigaciones orientadas de forma socio-histórica o cultural-histórica (Schor, 2011, p.11). La abstracción del contexto histórico y la estandarización de las relaciones entre actores hacen posible obtener una perspectiva de 'ojo de pájaro' sobre la estructura de la red y las posiciones relativas de los actores implicados. Mark Granovetter indicó que "la mayoría del comportamiento está estrechamente imbricado en redes de relaciones interpersonales" (Granovetter, 1985, p.504) y eso puede ser visto como una respuesta razonable a la situación presente (Granovetter, 1985, p.506). Es igualmente cierto tanto para las redes contemporáneas como para las históricas. En la investigación de redes históricas, con sus posibilidades analíticas limitadas, las redes sociales pueden ser comprendidas como potencialmente influyentes en las acciones de los individuos. Además, la existencia de lazos ausentes puede tanto ampliar como obstruir el rango de acción de un individuo. En este sentido compartimos una comprensión de las redes como modelos de espacios de posibilidades y limitaciones.

El desafío de la investigación de redes históricas es re-introducir el contexto histórico de nuevo una vez que el análisis formal ha sido realizado. Para concluir con estos comentarios metodológicos introductorios: mientras las estructuras de las redes a menudo pueden ser examinadas mejor por métodos formales y exploración visual, las acciones individuales y las estrategias de los individuos dentro de dichas estructuras requieren una aproximación cualitativa más tradicional. Por lo tanto ambas estrategias de investigación no se contradicen, sino que se complementan (Schnegg, 2010; Düring y Stark, 2011 defienden ideas similares).

\section{VennMaker: de los gráficos a los datos}

VennMaker es un programa informático para recolectar, visualizar y analizar redes sociales. La recolección de datos tiene lugar mientras se dibuja. Como en un programa de dibujo, el usuario dibuja la red personalmente. Durante el proceso de recolecta, el usuario pinta símbolos y líneas dentro de un area definida llamada "mapa digital de la red". 
Uno de los valores de este tipo de mapa de red reside en el rango de posibilidades para representar y almacenar información de la red. En comparación con las herramientas de papel y lápiz y otras herramientas, por ejemplo, el tamaño, color y formas de los nodos y de las relaciones entre nodos son fáciles de modificar. Por ello, los mapas digitales de redes pueden ser ajustados de forma flexible al proyecto de investigación. Dado que los datos son fáciles de modificar, son reutilizables y ajustables, por lo tanto reciclables para otros proyectos de investigación en cualquier otro momento (Gamper et al. en espera de publicación).

Los actores (o nodos) son visualizados como iconos en un espacio bidimensional. La información se muestra como texto utilizando diferentes elementos visuales como los iconos o las líneas. La comunicación visual permite la percepción simultánea de la información, mientras que la información codificada como caracteres de texto, p.e los cuestionarios en papel, sólo permite un decodificado lineal (Krempel, 2005).

Cada elemento visual representa una variable escalada discreta. Esto significa que el usuario define los atributos no relacionales y relacionales que pueden ser representados por los elementos visuales. Si el valor de dicho atributo cambia, el elemento visual correspondiente cambiará también y vice-versa. Por ejemplo, la importancia de una persona puede ser definida, por lo tanto, como un atributo con valores múltiples. Los valores pueden ser asociados con distintos tamaños de los iconos. Si el usuario cambia el tamaño del símbolo, el valor de la importancia también cambiará. Además, es posible distinguir entre diferentes tipos de relaciones codificadas por el color. Los elementos gráficos adicionales, p.e. círculos concéntricos, sectores y "quesitos", permiten la introducción de datos y la visualización. Las imágenes, p.e. los mapas históricos, pueden ser añadidos a partir de fuentes exteriores. Estos elementos visuales ayudan a estructurar y estandarizar la red. La conexión entre los valores de los atributos con los elementos visuales permite al usuario mantenerse a nivel visual cuando cambia los valores. Por lo tanto no necesita interrumpir el proceso de trabajo al cambiar el punto de vista, p.e. una visión tabular o una visión de matriz.

Cuantos más actores y relaciones se dibujen en el mapa digital de la red, más compleja se volverá su visualización, lo que puede conducir a una tasa de errores más alta en los resultados de la red. Esta cuestión de la complejidad creciente ha sido abordada utilizando filtros que pueden ser activados o desactivados de forma dinámica durante el proceso de colecta y análisis (Kronenwett and Schönhuth, 2011). 
Mientras el usuario dibuja la red, VennMaker calcula algunas métricas básicas de la red (p.e la densidad) al mismo tiempo. Cuando el usuario ha terminado el proceso de recolección de datos, el mapa de la red puede ser exportado como un fichero imagen, tabla o matriz a cualquier otro programa como Visione o UCINET ${ }^{5}$

\section{Aspectos estructurales de la familia Augusta y el destierro de Iulia la mayor en 2 AC}

En el otoño de 2 AC, después de un año importante para el refuerzo de su régimen, Augusto, el primer princeps romano, acusó públicamente a su hermana de adulterio y la desterró a una isla llamada Pandateria (Syme, 1974; Kienast, 2009). Al mismo tiempo, exilió a los presuntos adúlteros y otros, tanto del rango senatorial como del ecuestre (Vell. Pat. II 100, 5), a varios lugares. El más prominente, Iullus Antonius, el último hijo restante de Marco Antonio y miembro del círculo interior de la familia Augusta, fue ejecutado o conducido al suicido (Syme, 1974, p.20). Este escándalo, de considerable importancia política ha sido sujeto a un debate amplio $y$ controvertido entre los académicos modernos. Las fuentes antiguas proveen poca información del curso de los acontecimientos en general y de las ambiciones y motivos de los principales actores implicados en ambos bandos (sobre las fuentes véase Meise, 1969, pp5f y 17f). La discusión entre académicos modernos se caracterizó por una especulación sustantiva, dado que las medidas de Augusto afectaron a todo un grupo de hombres que pertenecían a familias distinguidas, pero las fuentes no aportan datos respecto a cualquier motivo político. Edmund Groag, a principios del siglo XX fue el primero en suponer que Augusto hubiera hecho uso de los lapsos de moral de su hija para cubrir la supresión de una conspiración política contra él y sus hijos adoptivos, Caius y Lucious Caesares, el primero de los cuales planeaba presumiblemente convertirse en su sucesor. Después, la tesis de Groag fue adaptada y desarrollada más allá por otros. Hoy se acepta ampliamente que la mayoría de los relatos encontrados en las fuentes antiguas sólo proveen una version oficial extremadamente sesgada del escándalo. Aunque algunas de las opiniones modernas difieren considerablemente, la mayoría de los académicos se refieren a una explicación basada en motivos políticos de un modo u otro. ${ }^{6}$ Dada la vaguedad de las fuentes antiguas nunca será posible esclarecer las circunstancias con una certeza absoluta. El propósito de este artículo es adoptar un punto de vista

\footnotetext{
5 Visone está disponible en internet en http://www.visone.info, Ucinet en http://www.analytictech.com/ucinet/ (ambos han sido accedidos el 6 de septiembre 2011).

${ }^{6}$ Algunos de ellos solo implícitamente al rechazar una base política y argüir que el adulterio fue el único crimen cometido. Recientemente (Bleicken 1998).
} 
diferente al ofrecer un modelo de red del domus Augusta. Algunos de los problemas en discusión serán revisados a la luz del análisis estructural basado en la teoría de redes para revelar su potencial para la historia antigua. ${ }^{7}$

En la historiografía clásica, eran los prosopógrafos los que se encargaban de examinar las relaciones de parentesco y su influencia en el comportamiento individual. Sin apoyo técnico, los investigadores individuales no podían tener una visión general de las estructuras familiares complejas en su conjunto. La prosopografía, por lo tanto, estrechó su alcance, focalizándose habitualmente en una persona y su entorno cercano, mientras que descuidó su imbricación en una red contextual mayor. La adaptación del análisis de redes sociales a la historiografía antigua abre la posibilidad de tomar en consideración los efectos de la red y por lo tanto revelar nuevas intuiciones sobre los motivos y restricciones del comportamiento individual que de otro modo hubiese quedado oculto.

Hasta ahora, los estudios más ricos a este respecto se derivan notablemente de la sociología histórica y la antropología social. Por ejemplo Douglas White aplicó el pgraph al linaje de los Israelitas de Canaán mencionados en el Antigüo Testamento (White y Jorion, 1992). Peter Bearman analizó las redes de parentesco de la élite terrateniente de Norfolk en los siglos 16 y 17 mediante la distribución de los atributos categóricos y blockmodels (Bearman, 1993). Su base de datos contenía varios cientos de actores a lo largo de un siglo, lo que hace que las visualizaciones no sean eficientes para el análisis. Padgett y Ansell también utilizaron el blockmodeling en su conocido estudio del auge de los Medici en la Florencia del Renacimiento (Padgett y Ansell, 1993). Los p-grafos pueden revelar normas sociales que afectan a las estructuras de parentesco, como las reglas de matrimonio y el tabú del incesto. Ese no es el propósito de este estudio particular, pero podría ofrecer resultados muy interesantes si se aplica a bases de datos históricas mayores. Nuestro estudio de caso opera en un nivel micro y contiene un número de actores comparativamente pequeño. Un análisis visual puede por lo tanto ser menos confuso que las tablas.

\footnotetext{
7 Hasta esta fecha hay pocos ejemplos de aplicación del análisis de redes sociales en la historia antigua (Alexander and Danowski, 1990) y (Ruffini, 2008), que es el más importante.
} 
Las visualizaciones bi-dimensionales de las estructuras familiares antiguas de una cierta complejidad, a menudo en forma de árbol, pueden ser algo difíciles de interpretar. Se vuelven incluso más difíciles de leer cuando personas de más de una familia están implicadas, casadas y divorciadas varias veces o tuvieron hijos con más de una pareja. En algunos casos es necesario representar a la misma persona más de una vez, lo que hace que el árbol sea más difícil de leer. A menudo se necesitan más de un árbol para ver las interdependencias entre varias familias. Beth Severy se ocupó de algunos de los problemas de la dinastía de Julio-Claudio utilizando un programa para visualizar los árboles familiares de la genealogía (Severy, 2003, p.65). Para el propósito de este artículo se han necesitado una gran variedad de técnicas de visualización que se pueden encontrar en los programas diseñados para el Análisis de Redes Sociales.

La figura 1 muestra el mapa de una red del círculo íntimo de la familia Augusta en el 2 A.C. y el linaje de sus miembros. ${ }^{8}$ Contiene relaciones más allá de los matrimonios y linajes y los hace distinguibles. Los segmentos coloreados y los círculos concéntricos se refieren a aspectos del orden social que eran válidos en la sociedad Romana. La primera separaba las cuatro gentes, o familias, unas de otras y por lo tanto sugiere una cierta cantidad de cohesión interna entre los nodos que contienen. ${ }^{9}$ La última alinea a los miembros de la familia de acuerdo con su posición en el linaje, para que cada círculo contenga la generación parental del círculo interior adyacente. Teniendo en cuenta la patria potestas, el poder de control global del patriarca sobre todos sus descendientes, que seguía estando en pleno poder durante la Roma de la república tardía, representa una parte importante de la vida social.

\footnotetext{
8 Los datos provienen de Paulys Realencyclopädie der classischen Altertumswissenschaft, una de las enciclopedias más importantes para la historia antigua. Como los tipos de consanguinidad entre los actores considerados son completamente existentes e indiscutibles, no es necesario derivarlos directamente de las fuentes antiguas. Se excluyen los medio hermanos.

9 Las siguientes figuras contienen tres actores, que no encajan en ninguna de las cuatro familias Fulvia, madre de Iullus Antonius, Scribonia, la primera esposa de Augustus, y Livia Drusilla, su segunda esposa. Están ligados a la familia con la que se desposaron primero.
} 
Augusto mantuvo una política familiar de "modelos de matrimonios y adopciones inusualmente endógamas" (Severy, 2003, p.62) que resultó, al final, en una separación casi completa de la coalición de las cuatro familias descritas del resto de la aristocracia romana. Tuvo un papel solitario para los planes de sucesión hasta Nerón (reino 54 - 68 D.C), el último emperador que se originó de la dinastía de Julio-Claudio y simultáneamente el primer emperador cuyo padre biológico no era un miembro de una de las cuatro familias de que nos ocupamos. Por estos motivos, las dinámicas dentro de esta parte interior de la familia Augusta puede ser examinada de forma separada. ${ }^{10}$

La red fue construida para centrarse en estas dinámicas internas del año 2 A.C. y por lo tanto excluye a los actores que todavía no pueden haber tenido un efecto real en la estructura. En este estudio de caso, una persona es definida como miembro del círculo interno del domus Augusta mediante 1. linaje directo a partir de una de las cuatro familias, ya sea materno o paterno, 2. matrimonio con una de las cuatro familias en algún momento de la vida, 3. nacimiento entre 90 A.C y 10 D.C. Además, Fluvia y Scribonia fueron incluidas meramente para completar las relaciones parentales de Iulia y su presunto adultero Iullus Antonius.

10 Marcus Vipsanius Agrippa (murió en 12 A.C.), el primer marido de Iulias, fue el abuelo materno de Calígula (reino 37 - 41 D.C.). La influencia de Agrippa no está incluida en esta red y sus hijos son tratados como Iulii/Octavii a causa de su madre Iulia. 


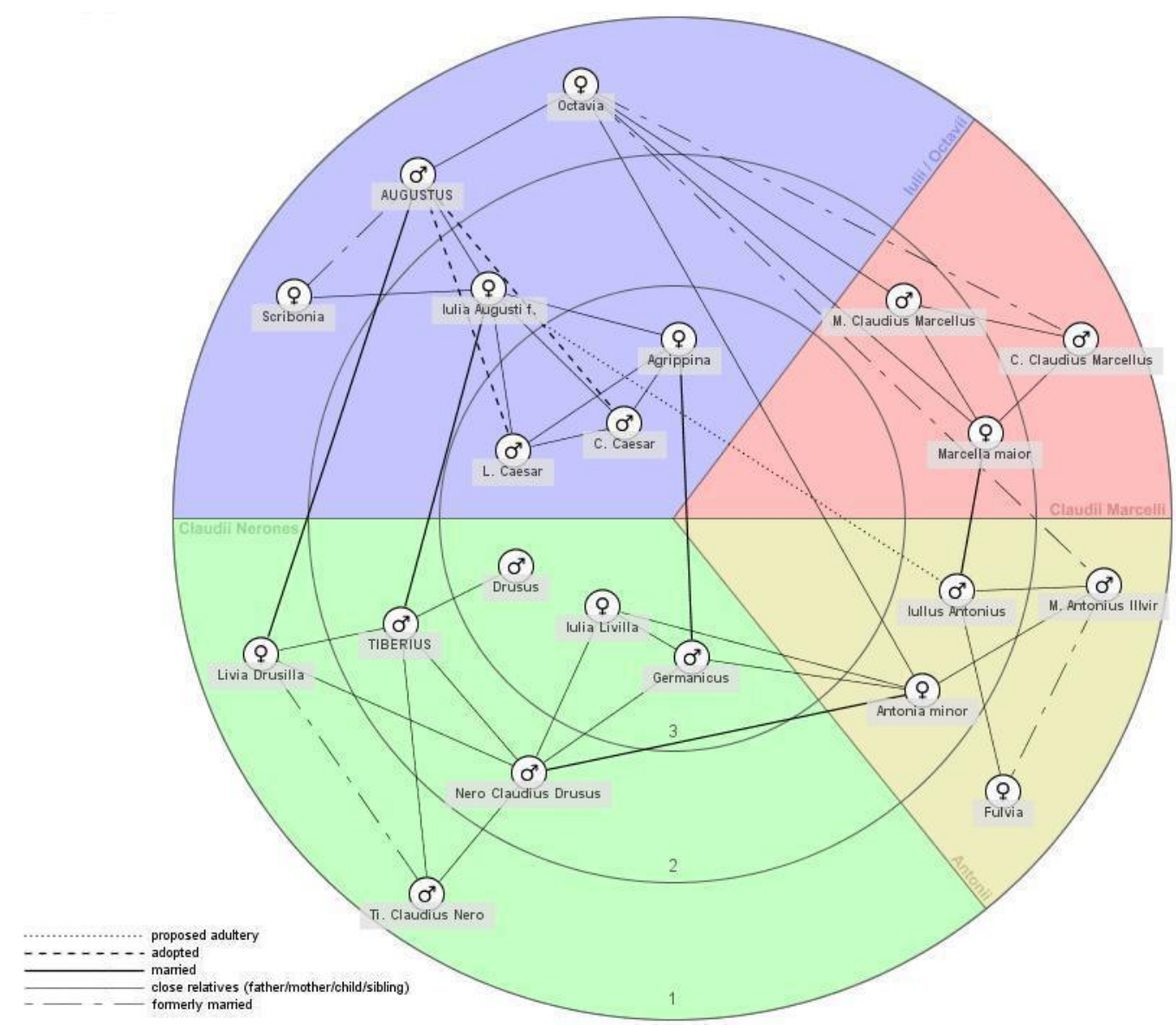

Figura 1. Relaciones de parentesco y linaje en el domus Augusta.

La figura 1 muestra claramente las consecuencias que tuvieron los "modelos de matrimonios" mencionados para la interconexión de las cuatro familias. Una mirada más detallada revela que casi todas las familias están interconectadas, los Claudii Nerones (uno de las dos partes patricias de la familia de Claudio) y los Claudii Marcelli (la parte plebeya de la familia de Claudio) son la única excepción. Las fuentes antiguas no proveen información sobre los matrimonios o adopciones entre estas dos familias en la República tardía.

También permite obtener nuevas ideas sobre la importancia de algunos miembros únicos de las familias, especialmente las mujeres, para la integridad de la estructura. Octavia, la hermana mayor de Augusto, por ejemplo, es la única miembro de la parte de la familia Iulia/Octavia que conecta con los Antonii y Marcelli. Corbier insistía en el papel de los miembros femeninos de la dinastía de Julio-Claudio en general para la transmisión de la legitimación de sus maridos. De acuerdo con la Figura 1, también eran esenciales para la coherencia de la estructura en su conjunto, desde el principio. Esto puede ser visto como un efecto adicional de su mayor esperanza de vida (Corbier, 1995). Comparada con otras familias, la 
Iulii/Octavii tiene la relación más estrecha con los Claudii Nerones, la familia de la esposa y hijos adoptivos de Augusto. Hay tres relaciones de matrimonio: el propio matrimonio de Augusto con Livia Drusilla, el matrimonio de su hija con su hijo adoptivo Tiberio y el matrimonio de su nieta Agrippina con Germanicus, hijo de Drusos el mayor y por lo tanto sobrino de Tiberio. Los Iulii/Octavii y los Claudii Nerones podrían ser considerados por lo tanto como el núcleo de la estructura de la familia Augusta y los Antonii y Marcelli como la periferia.

En la figura 2, todos los actores que ya han muerto en el 2 A.C. han sido retirados. Este mapa de la red muestra que, para esta fecha, la estructura de familia que Augusto había establecido desde su llegada al poder había sido altamente erosionada. La inesperada muerte temprana de importantes miembros de la familia afectó al grado de interconexión a través del matrimonio entre todas las familias excepto la de Julio-Claudio. De hecho los matrimonios de la familia de Julio-Claudio y un matrimonio entre Antonio-Marecello son los únicos que quedan del sistema de interconexiones que Augusto creó. Tiberio seguía vivo, pero se marchó a un exilio auto impuesto en 6 A.C. Su matrimonio con Iulia pasó por una crisis severa anteriormente y ya no era más que un lazo formal (Bleicken, 1998, pp. 634f; Sattler, 1969). 


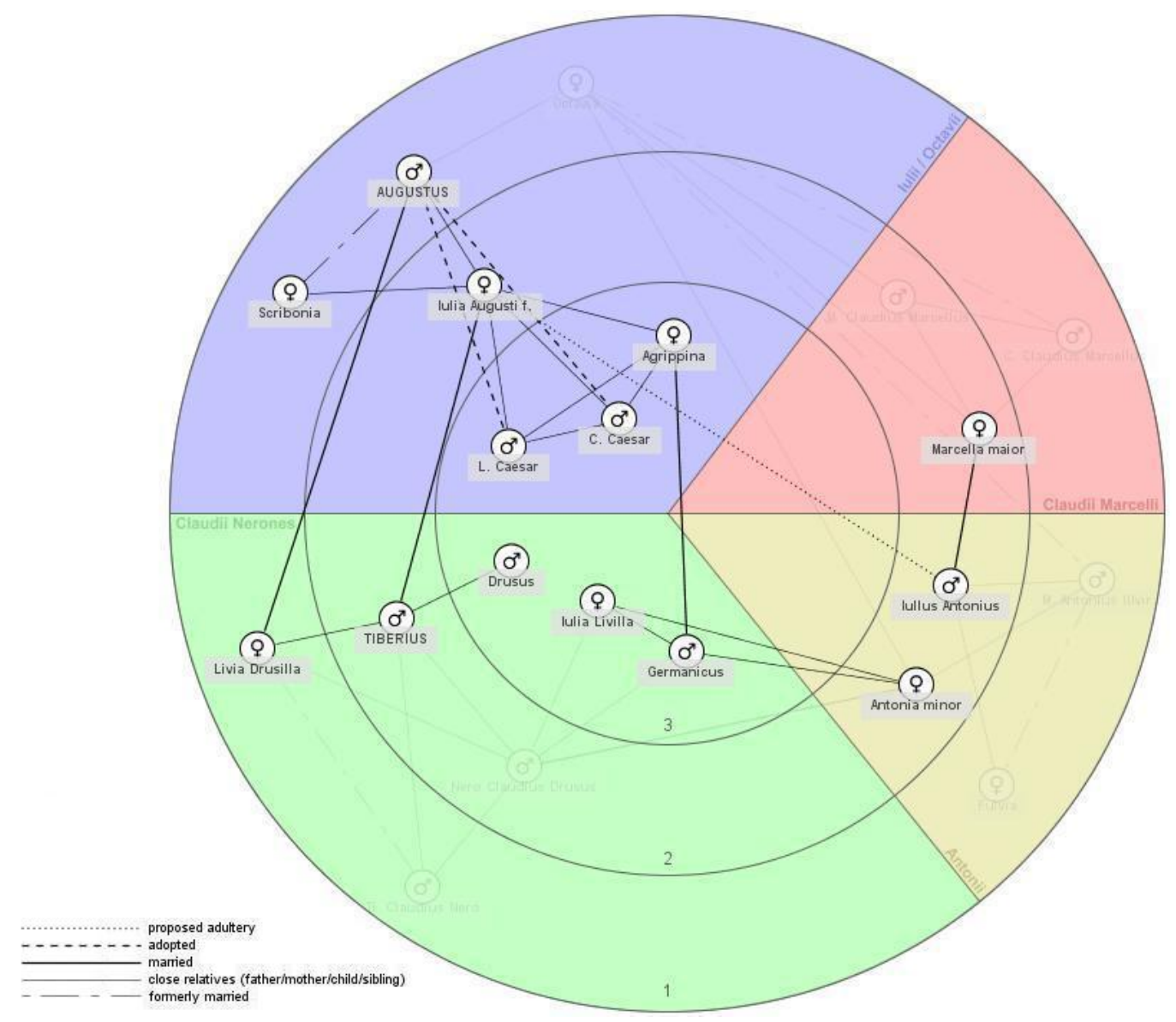

Figura 2. Domus Augusta tal como existía en 2 B.C.

Augusto acusó y condenó a su hija y sus amantes contra este contexto estructural. Como se mencionó más arriba, ningún bando tiene motivos distinguibles. El papel de Iulia en el sistema matrimonial de Augusto ha sido puesto de relieve a menudo. Su marido y por lo tanto el hijo político del princeps siempre tuvieron un papel importante en el reinado de Augusto (Tac. Ann. IV 40,6).

¿Que puede revelarnos sobre estas circunstancias una mirada a la estructura familiar? Iullus Antonius estaba pobremente conectado en el 2 A.C. Después de la muerte de Octavia, él y su mujer Marcella ya no estaban en contacto con la familia de Julio-Claudio. De hecho, el único lazo familiar fuerte que quedaba desde este punto de vista era su matrimonio. ${ }^{11}$ Las carreras de los otros miembros de la familia muestran que sólo aquellos que tenían una conexión cercana con Augusto o sus parientes más cercanos (es decir su mujer, hija y hermana) tuvieron la oportunidad

\footnotetext{
${ }^{11}$ En términos de redes: su centralidad de grado para relaciones de familia es de $1 \mathrm{y}$, si se le pone en el centro de una red egocentrada, su densidad aumenta levemente (de 0.22 a 0.24 ) al quitarlo. Sobre los conceptos de densidad y centralidad véase la literatura básica, por ejemplo Wasserman y Faust (1994, pp. 101-104, 178-202).
} 
de distinguirse en la carrera por los cargos administrativos o los mandos militares. Se podría decir que cuanto más corto era el camino hasta Augusto en la red familiar, tanto mejores oportunidades de carrera tenía un hombre en el domus Augusta.

El hecho de que Antonio era ambicioso en este aspecto es revelado por el hecho de que ya había sido cónsul con anterioridad (en 10 A.C). Después de que su madre adoptiva Octavia muriese en el 11 AC (el año en que fue elegido cónsul), aparece sólo una vez más en una función administrativa, como procónsul de Asia (RE I,2 Sp.2584). Ésta es una de las raras ocasiones en que un indicador empírico apoya una afirmación que por otro lado hubiera sido discutible en una fuente antigua. Plutarco ofrece pruebas de que Octavia había sido el motivo principal de la promoción política de su hijo adoptivo. ${ }^{12}$ Compuso su relato desde una perspectiva retrospectiva y son bien conocidas sus imprecisiones ocasionales y su estilo anecdótico. En este caso sin embargo parece tener un argumento porque podemos ver claramente que el final de la carrera política de Antonio coincide perfectamente con la muerte de su supuesta partidaria y, más importante, la separación resultante respecto al componente principal de la estructura familiar. Antonio no parece haber recibido ningún apoyo después de eso.

Una vez que Tiberio se había marchado, tal vez vio una oportunidad para volver a la escena política, pero convertirse en la nueva cabeza de familia a partir de una base estructural tan débil debió ser una opción muy poco realista, incluso para un hombre de la edad adecuada y de descendencia tan noble.

Se ha elucubrado respecto al momento en que Augusto escogió hacer publica dicha cuestión (Dettenhofer, 2000, p.179). Las puntualizaciones de Syme respecto a los motivos de Iulia para implicarse con Antonius tienen en cuenta implícitamente su punto de vista (Syme, 1974, p.25). Una mirada más detallada a las personas que forman parte del círculo más íntimo de la figura 2 muestra que los años entorno al 2 A.C. también fue un periodo crítico para Antonio. Esta nueva generación estaba a punto de llegar a una edad en la que se les permitía llevar a cabo las obligaciones que quisieran realizar. Caius Caesar había nacido en el 20 A.C. y se le había confiado una misión militar en las provincias del Este en el 1 A.C. Había sido designado cónsul para el año 1 D.C. (RE X,1 Sp.424-426). Lucius Caesar, su hermano menor, recibió la toga virilis, la toga de hombre, el mismo año en que su

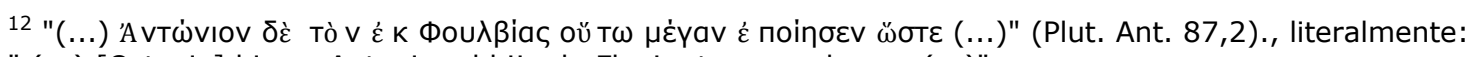

" (...) [Octavia] hizo a Antonio, el hijo de Fluvia, tan grande que (...)". 
madre fue desterrada (Kienast, 2009, p.31). Germanicus y Drusus, que en esa época tenían unos trece años (RE X,1 Sp.431f), eran los siguientes que alcanzarían la edad. Con esas cuestiones en mente, cualquiera que quisiera influir en la sucesión para favorecer a sus descendientes o para mejorar su posición en la estructura de la familia no tenía mucho tiempo para entrar en acción. La escasez de parientes masculinos capaces de Augusto estaba a punto de terminar.

Por supuesto las medidas severas que Augusto adoptó no pueden ser explicadas desde esta estructura familiar de forma positiva. Sin embargo se puede sugerir alguna evidencia para espacios de acción posibles. Tal como se menciona más arriba, Iullus Antonius estaba casi aislado en la estructura familiar después de la muerte de Octavia. Parecería que, de entrada, Augusto no quisiera considerarlo para cuestiones políticas importantes. Además, tras la muerte de Octavia, lo podía castigar sin tener en cuenta a otros miembros de la familia. Por el mismo motivo, Antonio podía desafiar la posición de Tiberio en la familia. Mientras éste estaba en Roma, hubiera sido un sinsentido. Una vez que Tiberio rompió con Augusto, se marchó a Rodas y por lo tanto estaba aislado en más de un sentido; tanto Iulia como Antonius no tenían motivos para tener en cuenta otras relaciones.

Con la muerte de Iullus Antonius y el destierro de Iulia maior, la estructura de la familia cambió más, esta vez no de forma accidental a causa de muertes naturales, sino por el control directo de Augusto. En este sentido, podemos ver a Augustus como un emprendedor de redes. Tras su transformación, la domus Augusta, tenía el aspecto mostrado en la figura 3. Scribonia, la madre biológica de Iulia acompañó voluntariamente a su hija al exilio. Una vez que el último miembro masculino de los Antonii había sido excluido de la familia los Marcelli estaban totalmente aislados y ya no tenían un papel político importante. 


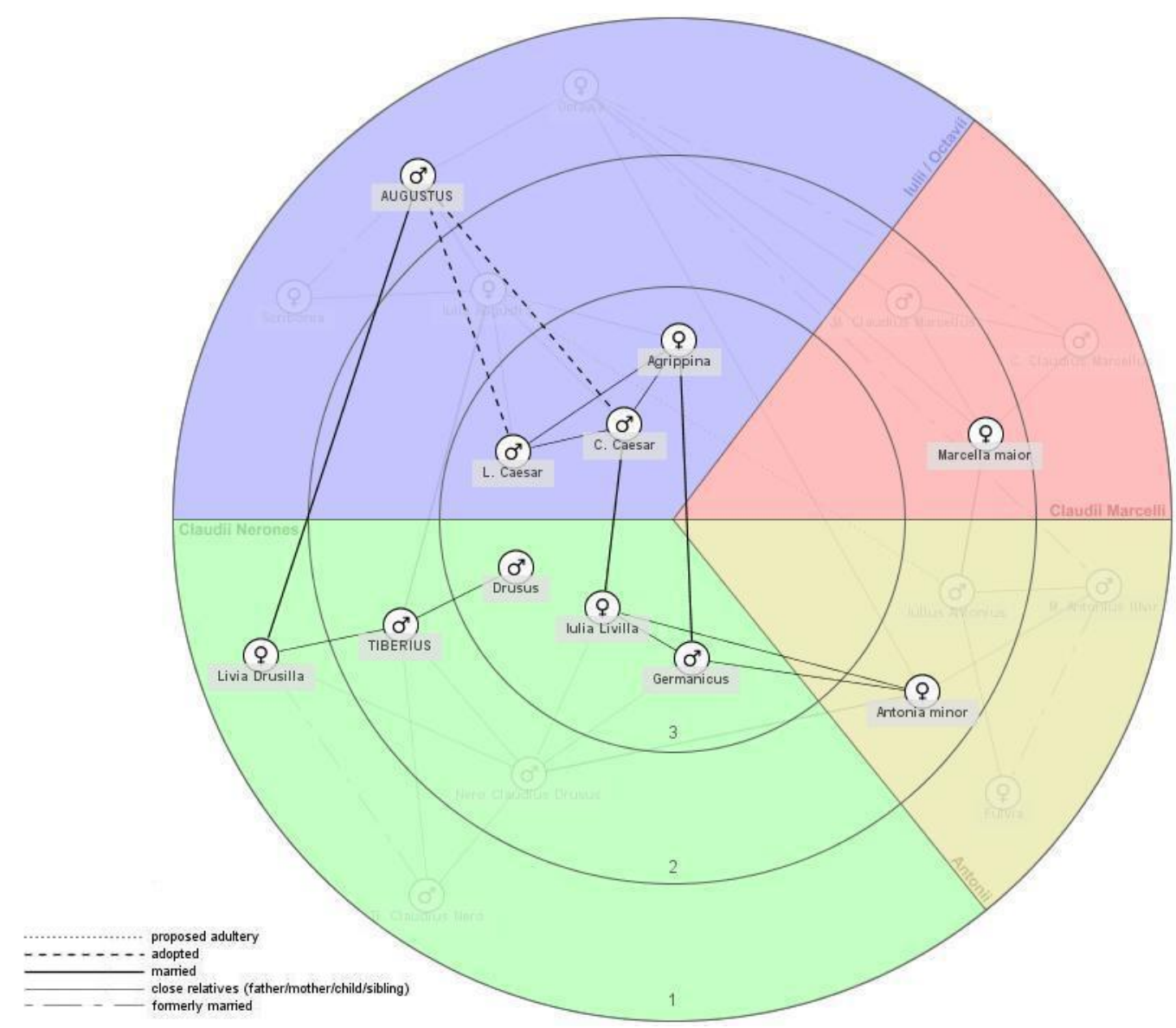

Figura 3. Domus Augusta in 1 B.C.

Además de exiliarla, Augusto divorció a su hija de Tiberio. Los investigadores modernos ya sugirieron hace tiempo que Augusto utilizó alegremente el caso para separarlo irrevocablemente de la familia (Groag, 1919, p.441). Esto hubiera podido ser una buena oportunidad para librarse de una persona non grata, pero también reducía la fuerza de la conexión entre las familias Juliana y Claudia, con sólo dos matrimonios cruzados restantes. Muy pronto, Augusto compensó esta pérdida al arreglar el matrimonio entre Caius Caesar y Iulia Livilla, una nieta de su mujer, que volvió a llevar los matrimonios Julio-Claudios a tres. Esto puede ser interpretado como una clara prueba para asumir que Augusto era plenamente consciente de los efectos de sus acciones y puede ser visto de forma justificada a la luz de su iniciativa reticular. Al contrario de las conclusiones de Padgett y Ansell sobre Cosimo de Medici $^{13}$, sostenemos que Augusto sabía desde el principio que controlar rodeaban." (Padgett y Ansell, 1993, p. 1310). 
su entorno reticular era crucial para mantener su mandato, que, al principio, estableció en gran medida a través de la fuerza militar. Una investigación más a fondo podría confirmar que sustituyó gradualmente la fuerza militar por el control de la red.

El propósito principal de este estudio de caso era mostrar cómo una aproximación estructural puede ser útil en la historia antigua ya que da una oportunidad a los investigadores de ver las temáticas familiares bajo otro punto de vista diferente. En la mayoría de los casos, no será posible explicar las acciones precisas directamente a partir de las estructuras de las redes. Sin embargo, como en el caso presentado aquí, puede ser útil ver las redes históricas como modelos de espacios de posibilidades y restricciones. En nuestro ejemplo, Augusto cambió su red de parentesco de acuerdo con sus necesidades y deseos y, de forma notable, contra la voluntad de otros miembros de la familia. Esto fue posible conforme perdieron sus apoyos estructurales.

\section{Redes personales de judíos para esconderse: una comparación sistemática}

Actualmente es bien sabido que una minoría de judíos logró sobrevivir al holocausto escondiéndose y con el apoyo de un grupo pequeño y diverso de personas que les ayudaron. Poco tiempo después del final de la Segunda Guerra Mundial, los historiadores, sociólogos, psicólogos (sociales) e investigadores de muchas otras disciplinas comenzaron a analizar las historias de ayuda y supervivencia y encontraron diferentes respuestas a lo que parecía ser la cuestión principal en juego: "¿Por qué decidieron ayudar los ayudadores?". Las fuentes utilizadas con mayor frecuencia fueron recolectadas por el memorial israelí Yad Vashem. La institución es famosa por haber discernido el título de "Righteous among the Nations" a los individuos que demostraron ayudar de forma altruista. ${ }^{14}$

${ }^{14}$ Se puede encontrar más información en Yad Vashem www.yadvashem.org (acceso el 8 de noviembre 2011). 
Muchos científicos sociales han llegado a la conclusión de que el comportamiento de ayuda era una consecuencia de algunas características comunes entre todos los ayudadores. Samuel y Pearl Oliner apuntaron que eran dirigidos por un sentido de la moralidad y el altruismo y que una forma específica de educación que incluía valores éticos y políticos fuertes podía explicar sus acciones (Oliner y Oliner, 1992). Otras personas miraron sus orígenes socio-demográficos, p.e. su educación y su riqueza (Seligman, 1992).

Sin embargo los historiadores han mostrado que los ayudadores no solo diferían en la cualidad moral de sus acciones sino también respecto a la intensidad de los modos en que eran activos (Benz et al., 1996-2004; Grabowski, 2008; Moore, 2010; Sémelin et al., 2011). Sus estudios confirman que los ayudadores venían de todo tipo de orígenes, tenían motivaciones diferentes, lo que ofrece una amplia variedad de razones para explicar su comportamiento, también tenían recursos y socializaciones variables. Los estudios de caso (Beer, 2010) y la historia de las fuentes disponibles sugieren que incluso los motivos aducidos por los ayudadores fueron objeto de reinterpretaciones conscientes o inconscientes y que no se les puede tener confianza necesariamente.

Tanto en Alemania como en los países ocupados, los ayudadores y los refugiados actuaron bajo una extrema presión de un entorno hostil y podían esperar ser arrestados inmediatamente en cuanto sus actividades atrajeran la atención de cualquier persona dispuesta a denunciarlos. Sin embargo, las consecuencias para los ayudadores, la amplitud de acción y los recursos disponibles variaban considerablemente entre Alemania y las zonas ocupadas así como entre estas últimas. Probablemente la diferencia más importante entre Alemania y las zonas ocupadas fuera la ausencia de organizaciones cuyas infraestructuras pudieran ser usadas para ayudar a los judíos y otros refugiados. ${ }^{15}$ El proyecto descrito aquí deja de lado la comparación internacional para realizar un análisis en profundidad de las estructuras de las redes que emergieron bajo condiciones similares, es decir en Berlín de 1942 en adelante. Aquí, la mayor parte de la gente eran o debían ser considerados nazis devotos; cualquier solicitud de ayuda debía, por lo tanto, ser realizada con mucha precaución y basándose en relaciones de confianza. Los refugiados se enfrentaban a chequeos regulares por parte de la policía y la Gestapo,

\footnotetext{
15 La excelente comparación de Bob Moore de las redes de apoyo en las zonas ocupadas del oeste muestra que la gran mayoría de todas las redes tenía sus raices en redes anteriores como las de caridad u organizaciones de scout, por ejemplo véase: Moore (2010), p. 111f, p. 160. En Alemania la mayoría de las organizaciones habían sido desmembradas o "gleichgeschaltet", es decir, sido sujetas a "nazificación".
} 
que primero trataba de encontrar a los judíos, luego a los jóvenes que hubieran desertado del Wehrmacht. Además, tenían que temer el Ilamado "Greifer", judíos presionados por la Gestapo para encontrar otros refugiados a quienes se les había prometido quedar libres de la persecución tanto ellos como sus familias (Tausendfreund, 2005).

Estos peligros reunidos, unidos a los esfuerzos del régimen por controlar los mercados negros y cualquier otra forma de comportamiento desviado, significaban que cualquier escrito sobre las actividades llevadas a cabo representaba una amenaza significativa. ${ }^{16}$ Los agentes de la Gestapo interrogaban a cualquiera que asociasen con actividades de apoyo para identificar a todos los colaboradores. Las transcripciones de dichos interrogatorios pueden ser muy informativas; sin embargo contienen (conscientemente) información falsa o equívoca. La mayoría de las fuentes disponibles fueron producidas después de la guerra. Un gran número de ayudadores y refugiados dieron cuenta de sus acciones cuando se aplicaron las reparaciones. Cuestionarios detallados preguntaban por sus actividades políticas, sus experiencias de persecución y los daños físicos y materiales, su implicación en actividades de resistencia, sus creencias religiosas y un resumen extenso. Después se les pedía que escribiesen sus historias. Estos documentos, diseñados con los refugiados y los combatientes de la resistencia en mente, debían demostrar la participación en actividades anti-nazi y casos de expropiación ilegal por parte del estado. No estaban previstas para descubrir las prácticas de ayuda y supervivencia. Cualquier información que los informantes hubiesen dado debe ser sopesada contra sus intereses por recibir una reparación por parte de una institución que no estaba actuando necesariamente en su mejor beneficio. En 1958, el senador de Berlín, Joachim Lipschitz, tuvo una iniciativa para honrar a los ayudadores en Berlín. Aquellos que pudieran presentar un estilo de vida honorable17 y dar muestras de sus acciones eran recompensadas con una pequeña renta y un reconocimiento público por su ayuda (Riffel, 2006). De nuevo, los administradores recogieron informes y datos sobre los ayudadores y los refugiados, que ahora están disponibles para la investigación. Comenzando con las solicitudes para las reparaciones, todas las fuentes se produjeron en contextos que animaban las historias de ayudadores virtuosos, dado que las instituciones respectivas excluyeron el reconocimiento de

16 A pesar de ello existe un pequeño número de relatos contemporáneos, principalmente diarios: Andreas-Friedrich, Ruth (2000). Der Schattenmann: Schauplatz Berlin; Tagebuchaufzeichnungen 19381948. Berlin: Suhrkamp; Behrend-Rosenfeld, Else R. (1945). Verfemt und verfolgt: Erlebnisse einer Jüdin in Nazi-Deutschland 1933 - 1944. Zürich: Büchergilde Gutenberg.

17 Se excluyó a las prostitutas de esta iniciativa. 
motivaciones ambivalentes o dudosas. Los informes de los supervivientes son más directos. Por supuesto se centran en sus historias de superviviencia; su objetivo es contar las historias a partir de su propio punto de vista, a menudo limitado, y por lo tanto no sin omisiones, distorsiones y memorias falsas.

Oliner and Oliner mostraron que aproximadamente dos tercios de todos los ayudadores cuyos casos fueron documentados en el memorial Israeli Yad Vashem respondieron a las solicitudes de ayuda (véase igualmente: Varese y Yaish, 2000). La gran mayoría de los ayudadores colaboraron con otros para facilitar su apoyo a los refugiados. ${ }^{18}$ Esto sugiere que la decisión de ayudar no era sólo una cuestión de personalidad, sino también de imbricación social.

El proyecto trata de contribuir a la investigación existente al tratar de comprender la decisión de ayudar y su práctica como un proceso social. En este proceso, los ayudadores respondían típicamente a las solicitudes de ayuda y utilizaron a compañeros para apoyar y reforzar su sistema de creencias, que les condujeron eventualmente a actuar de forma diferente de la mayoría de la sociedad en la que vivían. La mayoría de los estudios mencionados (Oliner y Oliner, 1992; Seligman, 1992; Varese y Yaish, 2000) pretendían medir el comportamiento de ayuda tanto estadísticamente como a través de la comparación de casos individuales. Esta aproximación trata de reconstruir, en una forma comparativa y por lo tanto formalizada, las redes sociales entre los ayudadores y los refugiados en Berlín para discutir su importancia, tanto en la motivación de ayudar como en la capacidad de los refugiados de mantener una vida sumergida. Los datos relacionales son usados para mapear literalmente las relaciones complejas que emergieron entre ayudadores $y$ refugiados $y$ entre refugiados. Todas las interacciones entre ayudadores y los recibidores de la ayuda fueron codificados en una base de datos que describe la práctica de la ayuda y la intensidad de las relaciones entre dos actores. Entre ellas se encuentra la información sobre formas y duración de ayudas específicas, la fecha de su primer encuentro y una categorización aproximada de sus motivos. ${ }^{19}$

\footnotetext{
18 La investigación en una base de datos pública sobre comportamientos de ayuda en Berlín compilada por el Gedenkstätte deutscher Widerstand confirma que los ayudadores aislados eran una pequeña minoría.

${ }^{19}$ Las categorías de la base de datos fueron desarrolladas al hacer el análisis de cuatro redes de apoyo distintas. Una vez que las categorías encajaron con las cuestiones de la investigación y las fuentes disponibles, todas las redes fueron codificadas de nuevo utilizando las categorías estandarizadas.
} 
Uno de los objetivos de este estudio es la comparación de las redes personales de los judíos que se escondían. VennMaker fue utilizado para explorar el potecial de las visualizaciones estandarizadas de redes personales. Se escogieron como estudios de caso dos informes escritos por una mujer judía de mediana edad y un hombre joven judío que sobrevivieron al Holocausto escondiéndose en Alemania. Ambos sobrevivieron con la ayuda de muchos gentiles que no conocían de antes. En este punto, el objetivo de la comparación era explorar las similitudes y las diferencias en las redes de ambos refugiados y poner a prueba las capacidades de VennMaker para las visualizaciones. El objetivo era desarrollar una representación a la vez densa y legible de las redes personales de los individuos para permitir al investigador tanto analizar el desarrollo de los lazos de un individuo a lo largo del tiempo como comparar varios individuos. ${ }^{20}$

Las visualizaciones de relaciones entre ayudadores y refugiados permiten explorar la complejidad de las relaciones y conectarlas con las acciones de los individuos con los desarrollos de estructuras más amplias. De este modo, la complejidad de las relaciones sociales deja de ser un obstáculo para convertirse en el objeto de investigación. Para reconstruir las relaciones entre los actores, es necesario evaluar diversas fuentes respecto a su credibilidad respectiva. Este proceso reduce necesariamente las fuentes históricas a la información sobre datos relacionales. Las estructuras relacionales resultantes, sin embargo, sólo pueden ser interpretadas de forma significativa cuando se consideran con la información detallada y específica de las fuentes originales. El estudio de caso presentado aquí está basado ampliamente en informes autobiográficos de los dos refugiados que podrían ser parcialmente validados con los tipos de fuentes mencionados antes. Las referencias cruzadas han mostrado que son verificables y precisos.

Para mapear la emergencia y uso de estas relaciones, se consideraron relevantes los siguientes aspectos: la forma de ayuda, el tiempo de ayuda, la intensidad de la relación entre ego y sus alteri, todas las relaciones conocidas entre los alteri, y su fluctuación. La multiplicidad de estas relaciones hace necesario expandir la representación esquemática de la información al espacio del mapa de la red : el algoritmo de muelle-imbricado que se usa habitualmente en otros programas de redes acerca los nodos que se consideran bien conectados entre sí; los nodos que considera mal conectados entre sí son alejados unos de otros. Sabemos de la

\footnotetext{
${ }^{20}$ Puede argumentarse que el desarrollo de las redes personales podía ser representado en una galería de seis mapas por red personal; la solución actual, sin embargo, utiliza menos espacio y permite que la comparación entre varias redes sea más fácil.
} 
imbricación global de un nodo porque consideramos su posición en relación con su distancia con otros nodos. Por ejemplo, si el nodo A y el nodo B estuvieran pobremente conectados, obviamente no importa si el nodo A está posicionado arriba a la izquierda y el nodo $B$ abajo a la derecha o lo contrario. Lo que importa es que están lejos uno de otro. En este proyecto, sin embargo, el espacio es utilizado para representar información adicional. Los segmentos de los mapas de la red representan «periodos de tiempo» de seis meses cada uno y (en círculos concéntricos) la cualidad de las relaciones entre ego y los alteri. El mapa muestra el desarrollo de las redes personales de la segunda mitad de 1942, en sentido de las agujas del reloj, hasta la primera mitad de 1945 (Figura 4).

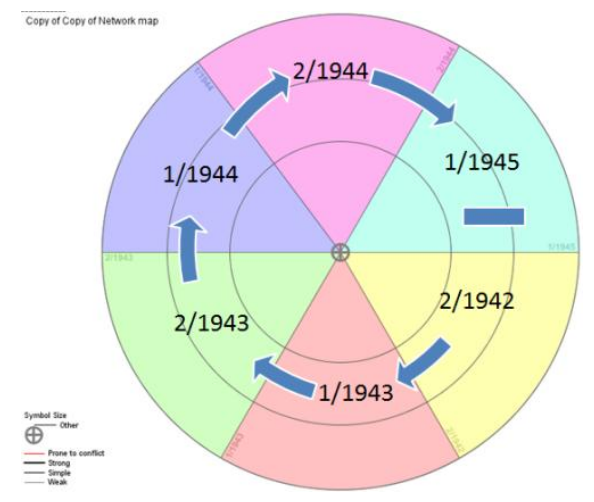

Figura 4. El tiempo está representado como sectores. Cada uno cubre un período de seis meses desde la segunda mitad de 1942 hasta 1945.

Aunque esta representación cíclica contradice nuestra comprensión del paso del tiempo lineal, tiene una gran ventaja: cada segmento tiene el mismo tamaño, lo que facilita la comparación dentro de una red y con otras redes. 


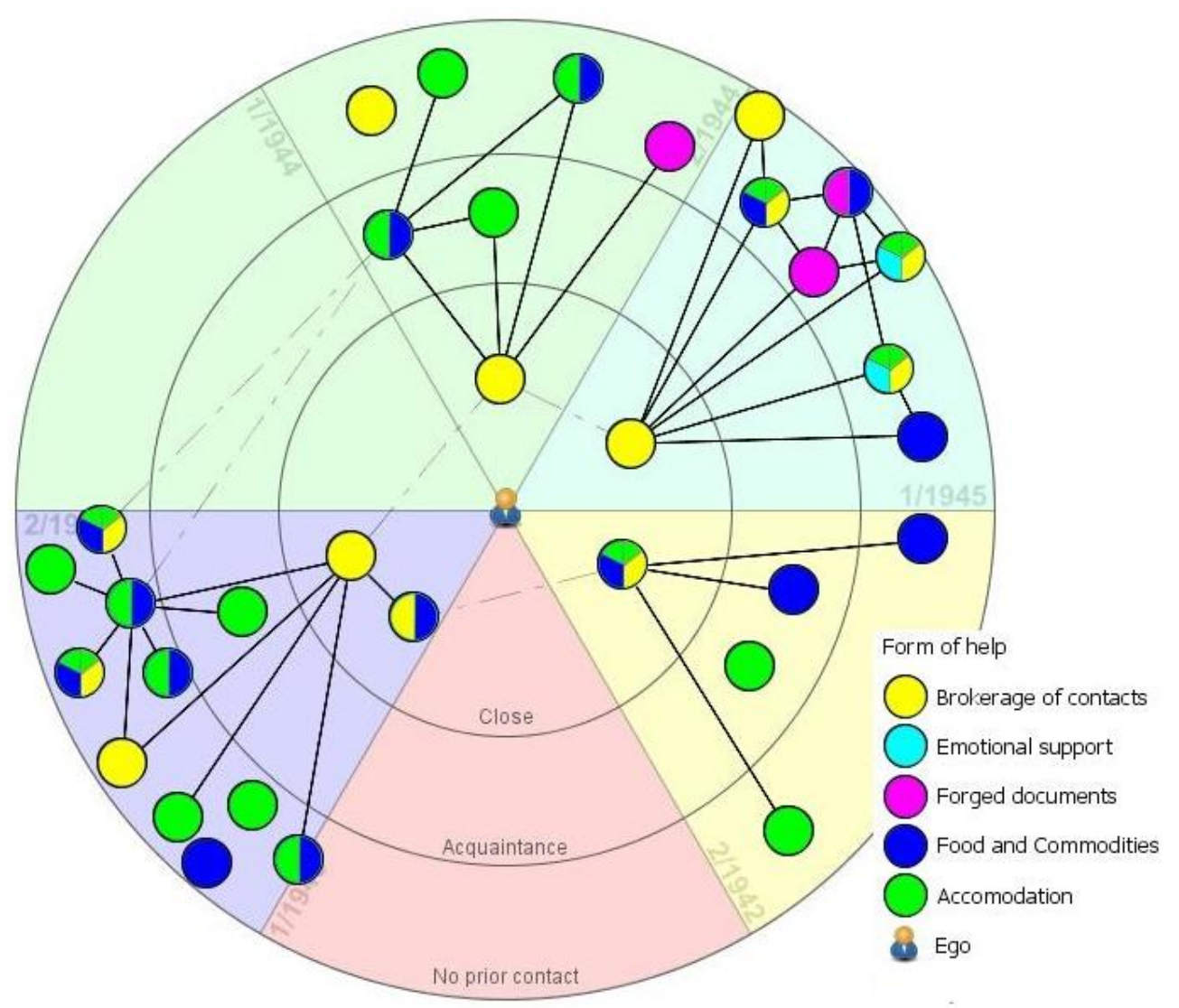

Figura 5. La red de Ralph Neumann.

Los amigos en los que ego confía están posicionados en el centro del círculo. Los conocidos $^{21}$ se encuentran en el segundo, los extraños en el tercer aro. Mientras que en la mayoría de los casos las palabras permiten evaluar la intensidad de las relaciones, hay algunos casos en que dicha categorización debe apoyarse en la interpretación de los historiadores y únicamente en el conocimiento del contexto. Algunas relaciones entre refugiados y sus ayudadores, por supuesto, se han identificado a lo largo del tiempo y se ha desarrollado la confianza. Este análisis, sin embargo, se concentra en las redes sociales pre-existentes y en su significado para sobrevivir. Por lo tanto sólo considera la cualidad de las relaciones en el momento en que el refugiado se escondió.

Las relaciones entre ego y sus alteri son presentadas por definición y no son representadas con líneas para evitar una imagen desordenada. Por otra parte, las relaciones entre alteri son visibles así como cualquier sub-estructura de la red. Sucede que los ayudadores están presentes en más de una franja de tiempo. Si,

${ }^{21}$ Definimos como "conocidos" a dos personas que se pueden identificar mutuamente y charlar. 
por ejemplo, la persona C provee de ayuda tanto en la segunda mitad de 1943 como en la primera mitad de 1944, habrá una línea de puntos entre el nodo " $C$ " de la franja de tiempo 2/1943 y el nodo "C" en 1/1944. Esto da información básica de la fluctuación de los ayudadores y permite distinguir entre ayudadores nuevos y ayudadores previos.

El color de los actores representa su forma de ayuda. El amarillo representa la intermediación entre contactos nuevos, el verde el alojamiento, el azul la comida y las cartillas de racionamiento de comida, el violeta los documentos y el turquesa el apoyo emocional mencionado explícitamente. Los ayudadores que contribuyeron de más de un modo tienen nodos con dos o tres colores. Esto es posible porque VennMaker puede importar iconos personalizados ${ }^{22}$.

La figura 5 muestra la red personal de Ralph Neumann. Neumann, su hermana y su madre evitaron la deportación y fueron a esconderse a Berlín en febrero de 1943 (Neuman, 1994). La madre de Neumann fue sin embargo arrestada unas semanas después y murió bajo custodia en junio de 1943. Leo Fraines, un amigo de Ralph Neumann y compañero de trabajos forzados, le encontró un escondite en una granja fuera de Berlín, donde Ralph estuvo a salvo durante varias semanas. A partir de entonces, su hermana Rita le encontró un lugar con Agnes Wendland, su propia ayudadora en Berlín. Wendland hizo de intermediara con otros ayudadores en Berlín y Ralph Neumann consiguió sobrevivir hasta el final de la guerra. Hay una brecha en el informe en la primera mitad del 1944 que se explica mejor con una fase de relaciones relativamente estables. Podemos asumir que a lo largo de 1944, Ralph era apoyado continuamente por la familia Wendland y su red; mencionó nuevos contactos sólo hacia finales del año.

La red personal de Erna Segal fue escogida como la segunda visualización (para una discusión más detallada véase Düring, 2011). Ella, su marido y dos hijos adolescentes decidieron esconderse en el verano de 1942. Aunque pronto tuvieron que separarse, lograron verse con regularidad (Segal, 1956). Los Segal sobrevivieron con ayuda de viejos conocidos que les recomendaron a nuevos ayudadores. Entre los nuevos ayudadores se encuentra el Dr. Fritz Aub, que ayudó tanto a la familia Segal como a Ralph y a Rita Neumann; sin embargo, los Segal y los Neumann no se conocieron.

\footnotetext{
22 Agradezco a Claire Lemercier la sugerencia de las dimensiones de ayuda dis-continua y los nodos con varios colores para esta visualización.
} 


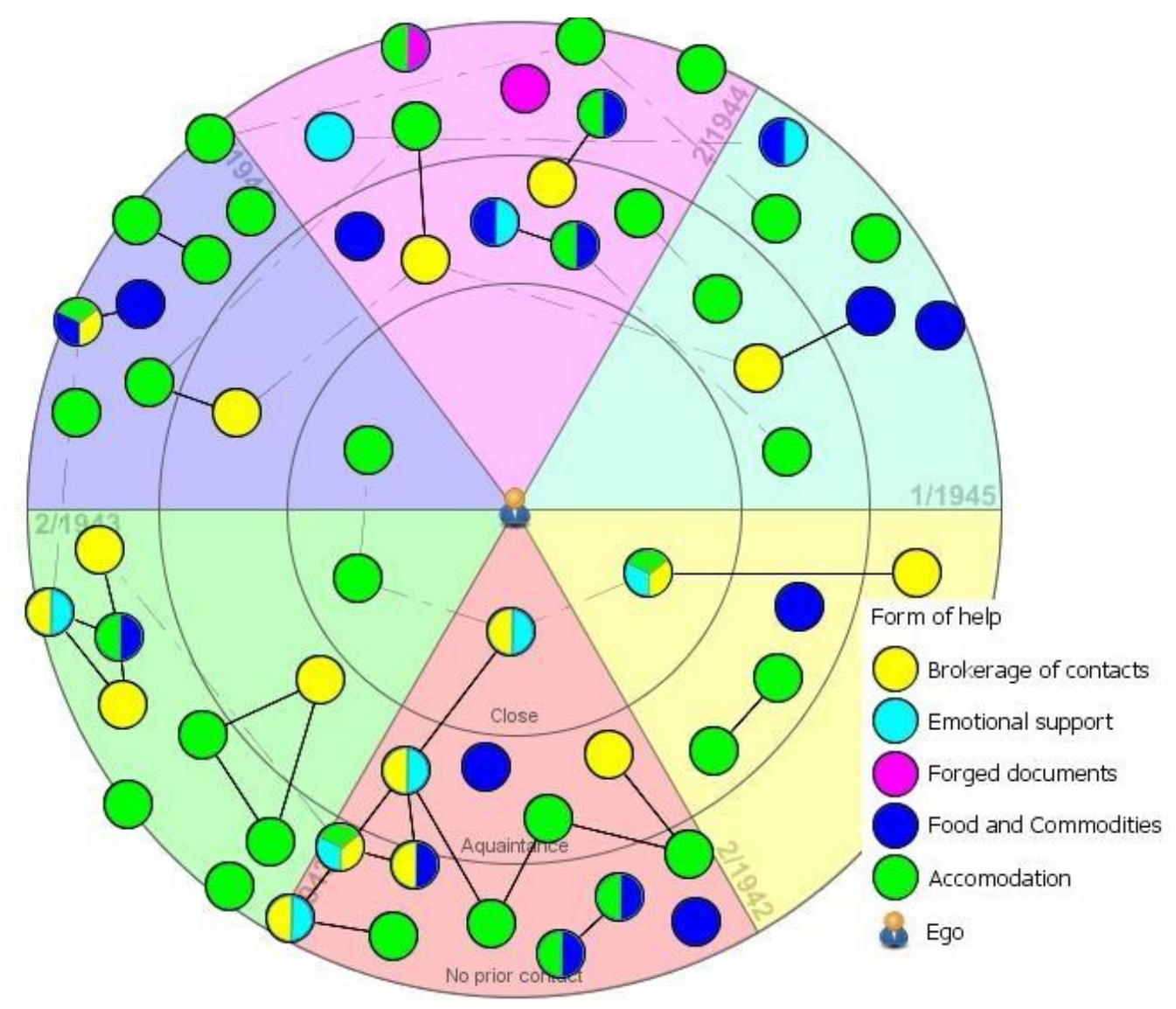

Figura 6. La red personal de Erna Segal.

Una comparación entre las redes de Ralph Neumann y la de Erna Segal revela las siguientes similitudes: ambas comienzan sus fase de esconderse con pocos ayudadores, que conocen a través de amigos de confianza. Estos "lazos fuertes" en el sentido de Granovetter (Granovetter, 1973), dieron a los refugiados acceso a nuevos ayudadores, algunos de los cuales se convirtieron en ayudadores de confianza. La mayoría de los ayudadores aparecen únicamente en una franja de tiempo, la proporción de ayudadores constantes es relativamente baja en el conjunto del tiempo.

Sobrevivir durante el Holocausto dependía de la confianza mutua entre refugiados y ayudadores. Un ayudador de confianza, y por lo tanto oponente a los nazis, con frecuencia conocía a otros. Una simple recomendación permitía a los refugiados entrar en esas pequeñas redes encubiertas de opositores de los nazis. Estas redes típicamente no se apoyaban en mucho mas que la oposición compartida contra los nazis. La presencia de un refugiado que necesitaba ayuda urgentemente podía transformar los oponentes pasivos en activos. Estos continuaban reclutando a otros ayudadores y dándoles ejemplo. Este simple mecanismo hizo posible que extraños de mentalidad similar pudieran construir relaciones de confianza, incluso dentro de 
un sistema totalitario opresivo. En 1943, Erna Segal se pudo beneficiar de una cadena de siete de estas recomendaciones, lo que le dió acceso a diferentes círculos sociales y eventualmente a ayudadores muy potentes. Para 1944 la gran fluctuación de los ayudadores en su red la obligó a encontrar nuevos ayudadores continuamente y a persuadirlos de que se volvieran activos. A primera vista, Ralph Neumann parecía haber estado en una mejor posición. Sin embargo su imbricación en una red pre-existente implicaba un riesgo considerable para él y sus ayudadores. Los interrogatorios sin piedad de la Gestapo, y a menudo la tortura, implicaban a menudo que el arresto de un refugiado condujera al fallecimiento de la red completa, incluyendo a la mayoría de los ayudadores y otros refugiados. Este es el motivo por el que Neumann se pasó a otra red en 1945. Había sido arrestado, logró escapar de la prisión y fue introducido en la segunda red por un ayudador de confianza que no había estado asociado con la primera red. Ni Segal ni Neumann tuvieron acceso a los tan necesarios documentos falsificados hasta finales de 1944 y por lo tanto no pudieron vivir bajo identidades falsas o atravesar los controles policiales en la calle. Esto significaba un riesgo significativamente mas alto de detección y menos libertad para moverse en la ciudad. Especialmente Ralph Neumann hubiera podido ser considerado soldado desertor.

Estos resultados nos conducen a varias hipótesis. Pocos actores de confianza daban acceso al primer contacto con ayudadores nuevos, lo que indica que los refugiados no se podían apoyar en otros amigos o familia de confianza, para esconderlos ${ }^{23}$. La vida clandestina no significaba necesariamente pasividad. Los esfuerzos de Erna Segal para acercarse de ayudadores potenciales y para poner en marcha numerosas recomendaciones entre ellos muestra que el apoyo a un pequeño número de refugiados era posible incluso dentro del régimen nazi. Ralph Neumann fue más pasivo y tuvo la ayuda de las relaciones de su hermana y Leo Fraines con otros ayudadores. En ambos casos, las contribuciones esenciales vinieron de personas que también eran víctimas de persecución, lo que subraya el significado de la autoayuda judía. El apoyo de la familia Wendland y de su red de amigos de confianza ofreció recursos muy necesarios a Neumann, pero también muestra el peligro de ser detectado a través de las conexiones que se tienen con las redes de apoyo. Obtener acceso a los ayudadores a través de una combinación de lazos fuertes era esencial para estos dos y muchos otros casos. También aparece en ambas redes que algunos

\footnotetext{
23 En el caso alemán, esto se explica por la segregación que había entre "arios" y "judíos" y el hecho de que la mayoría de los familiares de los refugiados ya habían sido deportados para 1942.
} 
ayudadores eran más activos que otros y actuaron como intermediarios entre los ayudadores y puntos de contacto para los refugiados.

En conjunto, las visualizaciones de VennMaker ofrecen una visión general de las características clave de las redes personales. La traducción del comportamiento de ayuda informado en datos relacionales nos ayuda a alejarnos del aislamiento de casos únicos. La estandarización y la simplificación permiten que las estructuras sociales se vuelvan visibles y comparables. Obviamente, una reducción de la información tan rígida hace que la contextualización de cualquier resultado en las fuentes primarias sea inevitable. La información que falta y los valores perdidos como en el caso de Ralph Neumann - se vuelve igualmente aparente. Contrastando con las visualizaciones corrientes que se apoyan en algoritmos de muellesimbricados o similares, esta aproximación utiliza el espacio para representar tanto el tiempo como la calidad de las relaciones. La posición de los actores cerca o lejos de ego es intuitiva y - como efecto lateral - agrupa a los alteri del mismo modo. Es de particular valor el poder organizar un número de "franjas de tiempo" en el sentido de las agujas del reloj. Los cambios y las continuidades se hacen visibles de un vistazo y revelan el desarrollo de una red personal a lo largo del tiempo. Por encima de la mayoría de las herramientas de visualización existentes, VennMaker permite finalmente a los usuarios mostrar individuos que aparecen más de una vez en un mapa de red, con atributos variables - una precondición esencial para esta aproximación de la visualización de la dinámica de las redes personales.

\section{Conclusión}

Este artículo trata sobre el potencial de VennMaker como herramienta para el análisis histórico. A partir de dos estudios de caso hemos explorado su aplicabilidad para dos sub-disciplinas históricas, fuentes y cuestiones de investigación. Ambos estudios de caso han mostrado ejemplos en los que la imbricación en redes sociales afectaba a la acción de actores históricos.

El primer estudio de caso de las relaciones de la familia de Augusto mostraba que los mapas de las redes y su exploración visual pueden añadir nuevas perspectivas a viejos problemas. La red muestra claramente cuán aislado se encontraba Iullus Antonius en el domus Augusta una vez que murió su madre adoptiva. Por lo tanto el esfuerzo de re-establecer una relación con Iulia debería ser interpretado como un intento de reconectarse con el componente principal de la familia Augusta para volver a obtener poder político. También los hallazgos en la red coinciden perfectamente con los datos ofrecidos por una fuente antigua, que sin embargo 
tiene fama de ser poco precisa en términos de detalle. Aunque no tenemos otras pruebas antiguas, podríamos concluir, a partir del modelo de la red, que Plutarco se refería a un rumor, al menos plausible, que todavía debía circular en su época.

El segundo estudio de caso muestra cómo pueden servir las visualizaciones de redes personales de judíos que se escondían durante el Nacional Socialismo para comprender los comportamientos de ayuda. Los refugiados dependían de fuentes que sólo podían obtener a través de contactos con ayudadores de confianza. VennMaker ha sido utilizado para visualizar y comparar la forma de la ayuda y la intensidad de las relaciones entre los refugiados y sus ayudadores a lo largo del tiempo. Se ha mostrado que las relaciones pre-existentes, la auto-ayuda y las recomendaciones de conocidos y extraños conducía a nuevos contactos y por lo tanto a la emergencia de relaciones de confianza entre extraños.

VennMaker permite dibujar y analizar de forma intuitiva las redes sociales sin requerir que los usuarios posean conocimientos técnicos específicos. Los estudios de caso muestran que el programa se puede adaptar con facilidad a una variedad de intereses de investigación, fuentes y tipos de estructuras sociales, ya sean redes ego-centradas o socio-centradas. Los círculos concéntricos, los segmentos del círculo y la función de superposición de la red pueden ser utilizados para representar una gran variedad de relaciones sociales en el tiempo y el espacio.

Sin embargo el programa tiene sus limitaciones. VennMaker pierde sus ventajas respecto a otros programas comparables cuando hay muchos actores y relaciones que representar; sólo puede mostrar redes de complejidad limitada. Cuanto más grandes son las estructuras de las redes, más difícil es representarlas dentro del marco del mapa y posicionar a los actores y sus relaciones. Mientras que demasiada información puede hacer que un mapa de red se vuelva ininteligible para observadores y audiencia sin formación, los investigadores pueden seguir encontrando maneras de recoger información a partir de ellos basándose en su experiencia y en el conocimiento de los contextos.

Al no proponer modelos predefinidos, VennMaker anima a los investigadores a que reflexionen sobre sus propios datos, a que exploren diferentes maneras de visualizarlos $y$, de este modo, puede contribuir a que aparezcan nuevas cuestiones de investigación. Vemos VennMaker principalmente como una herramienta heurística que apoya la recogida e interpretación de datos. Su capacidad para visualizar relaciones de forma rápida y sin esfuerzos permite a los investigadores ganar una nueva perspectiva diferente respecto a su campo de estudio. 


\section{Bibliografía}

Alexander, Michael C. and Danowski, James A. (1990). "Analysis of an ancient network: Personal communication and the study of social structure in a past society". Social Networks, no 12, pp. 313-335.

Andreas-Friedrich, Ruth (2000). Der Schattenmann: Schauplatz Berlin. Tagebuchaufzeichnungen 1938-1948. Berlin: Suhrkamp.

Barkey, Karen and Rossem, Ronan van (1997). "Networks of Contention: Villages and Regional Structures in the Seventeenth-Century Ottoman Empire". The American Journal of Sociology, no 102, pp. 1345-1382.

Bearman, Peter (1993). Relations into Rhetorics: Local Elite Social Structure in Norfolk, England: 1540-1640, (American Sociological Association, Rose Monograph Series) New Brunswick, NJ: Rutgers University Press.

Beer, Susanne (2010). "Helene Jacobs und die 'anderen Deutschen'. Zur Rekonstruktion von Hilfeverhalten für Juden im Nationalsozialismus", in SchmidtLauber, Brigitta; Schwibbe, Gudrun (Ed.). Alterität. Erzählen vom Anderssein. Göttingen: Schmerse (Göttinger kulturwissenschaftliche Studien, n 4), pp. 85110.

Behrend-Rosenfeld, Else R. (1945): Verfemt und verfolgt: Erlebnisse einer Jüdin in Nazi-Deutschland 1933 - 1944. Zürich: Büchergilde Gutenberg.

Benz, Wolfgang et al. (Ed.) (1996-2004). Solidarität und Hilfe für Juden während der NS-Zeit, (Volumes 1-7). Berlin: Metropol.

Bleicken, Jochen (1998). Augustus. Eine Biographie, Berlin: Alexander Fest Verlag.

Boyer, Christoph (2008). "Netzwerke und Geschichte: Netzwerktheorien und Geschichtswissenschaften", in Unfried, Berthold (Ed.). Transnationale Netzwerke im 20. Jahrhundert: Historische Erkundungen zu Ideen und Praktiken, Individuen und Organisationen. (ITH-Tagungsberichte, $\mathrm{n}^{\circ}$ 42) Leipzig: AVA Akad. Verl.-Anst, pp. 47-58.

Brudner, Lilyan and White, Douglas (1997). "Class, Property and Structural Endogamy: Visualizing Networked Histories". Theory and Society, no 26, pp. 161208. 
Corbier, Mireille (1995). "Male power and legitimacy through women: the domus Augusta under the Julio-Claudians", in Hawley, Richard and Levick, Barbara (Ed.). Women in Antiquity, London New York: Routledge, pp. 178-193.

Dettenhofer, Maria H. (2000). Herrschaft und Widerstand im augusteischen Principat. Die Konkurrenz zwischen res publica und domus Augusta, (Historia Einzelschriften, $\left.n^{\circ} 140\right)$ Stuttgart: Franz Steiner Verlag.

Düring, Marten (2011). "Das Dilemma zwischen Effizienz und Sicherheit: Über die Beziehungen zwischen Verfolgten des Nationalsozialismus und ihren Helfern". informationen. Wissenschaftliche Zeitschrift des Studienkreises Deutscher Widerstand 1933-1945, no 73, pp. 19-24.

Düring, Marten and Keyserlingk, Linda (forthcoming). "Netzwerkanalyse in den Geschichtswissenschaften. Historische Netzwerkanalyse als Methode für die Erforschung von historischen Prozessen", in Schützeichel, Rainer and Jordan, Stefan (Ed.). Prozesse - Formen, Dynamiken, Erklärungen. Wiesbaden: VS Verlag für Sozialwissenschaften.

Düring, Marten and Stark, Martin (2011). "Historical Network Analysis", in Barnett, George and Golson, J. Geoffrey (Ed.). Encyclopedia of Social Networks. London: Sage, pp.593-595.

Franzosi, Roberto (1996). "A Sociologist Meets History. Critical Reflections upon Practice". Journal of Historical Sociology, no 9, pp. 354-392.

Gamper, Markus and Schönhuth, Michael and Kronenwett, Michael (forthcoming). "Bringing qualitative and quantitative data together", in Safar, Maytham and Mahdi, Khaled (Ed.). Social Networking and Community Behavior Modeling: Qualitative and Quantitative Measures. Hershey: IGI Global.

Gorißen, Stefan (2006). "Netzwerkanalyse im Personenstandsarchiv? Probleme und Perspektiven einer historischen Verflechtungsanalyse", in Joergens, Bettina and Reinicke, Christian (Ed.). Archive, Familienforschung und Geschichtswissenschaft: Annäherungen und Aufgaben. (Veröffentlichungen des Landesarchivs NordrheinWestfalen, $\left.n^{\circ} 7\right)$ Düsseldorf: Landesarchiv Nordrhein-Westfalen, pp. 159-174.

Grabowski, Jan (2008). Rescue for money. Paid helpers in Poland, 1939 - 1945 (Search and research, $n^{\circ} 13$ ). Yad Vashem: Jerusalem. 
Granovetter, Mark (1985). "Economic Action and Social Structure: The Problem of Embeddedness". American Journal of Sociology, n 91, pp. 481-510.

Granovetter, Mark (1973). "The Strength of Weak Ties". The American Journal of Sociology, no 78, pp. 1360-1380.

Groag, Edmund (1919). Studien zur Kaisergeschichte III. Der Sturz der Iulia. Wiener Studien, no 41, pp. 74-88.

Grommes, Gerald (2008). "Netzwerke und Geschäftsstrukturen kastilischer Messebankiers im 16. Jahrhundert",Clemens, Gabriele B. (Ed.). Schuldenlast und Schuldenwert. Kreditnetzwerke in der europäischen Geschichte 1300-1900. (Trierer Historische Forschungen, n 65), Trier: Kliomedia, pp. 85-107.

Kienast, Dietmar (2009). Augustus. Prinzeps und Monarch, Darmstadt: Wissenschaftliche Buchgesellschaft.

Krempel, Lothar and Lipp, Carola (2001). "Petitions and the Social Context of Political Mobilization in the Revolution of 1848/49. A Microhistorical Actor Centered Network Analysis". International Review for Social History, no 46, Supplement 9, pp. 151-169.

Krempel, Lothar (2005). Visualisierung komplexer Strukturen. Frankfurt: Campus Verlag.

Meise, Eduard (1969). Untersuchungen zur Geschichte der Julisch-Claudischen Dynastie (Vestigia, $\mathrm{n}^{\circ} 10$ ), München: Beck.

Moore, Bob (2010). Survivors. Jewish self-help and rescue in Nazi-occupied Western Europe. Oxford: New York.

Neumann, Ralph (1994). Erinnerungen an meine Jugendjahre in Deutschland 19261946, (Beiträge zum Widerstand 1933-1945), Berlin: Gedenkstätte deutscher Widerstand.

Neurath, Wolfgang and Krempel, Lothar (2008). "Geschichtswissenschaft und Netzwerkanalyse: Potentiale und Beispiele", in Unfried, Berthold (Ed.). Transnationale Netzwerke im 20. Jahrhundert: Historische Erkundungen zu Ideen und Praktiken, Individuen und Organisationen. (ITH-Tagungsberichte, $\mathrm{n}^{\circ}$ 42) Leipzig: AVA Akad. Verl.-Anst., pp. 59-79. 
Oliner, Samuel P. and Oliner, Pearl M. (1992). The Altruistic Personality. Rescuers of Jews in Nazi Europe, New York: Free Press.

Padgett, John F. and Ansell, Christopher K. (1993). "Robust Action and the Rise of the Medici, 1400 - 1434". American Journal of Sociology, no 98, pp. 1259-1319.

Reitmayer, Morten and Marx, Christian (2010). "Netzwerkansätze in der Geschichtswissenschaft", in Stegbauer, Christian and Häußling, Roger (Ed.). Handbuch Netzwerkforschung. Wiesbaden: VS Verlag für Sozialwissenschaften, pp. 869-880.

Reupke, Daniel and Volk, Claudia (forthcoming). "Von der Akte zum Netzwerk Erfahrungsberichte aus der Werkstatt des Historikers", in Schönhuth, Michael and Gamper, Markus and Kronenwett, Michael and Stark, Martin (Ed.). Vom Papier zum Laptop - Perspektiven elektronischer Tools zur partizipativen Visualisierung und Analyse sozialer Netzwerke.

Riffel, Dennis (2006). Unbesungene Helden: Die Ehrungsinitiative des Berliner Senats 1958 bis 1966. Berlin: Metropol.

Ruffini, Giovanni (2008). Social networks in Byzantine Egypt, Cambridge: Cambridge University Press.

Sattler, Peter (1969). "Julia und Tiberius. Beiträge zur römischen Innenpolitik zwischen den Jahren 12 v. Und 2 n. Chr.", in Schmitthenner, Walter (Ed.). Augustus (Wege der Forschung, $n^{\circ} 128$ ), Darmstadt: Wissenschaftliche Buchgesellschaft, pp. 586-530.

Schnegg, Michael (2010). "Strategien und Strukturen. Herausforderungen der qualitativen und quantitativen Netzwerkforschung", in Gamper, Markus and Reschke, Linda (Ed.). Knoten und Kanten. Soziale Netzwerkanalyse in Wirtschaftsund Migrationsforschung. Bielefeld: transcript, pp. 55-75.

Schor, Adam M. (2011). Theodoret's People. Social Networks and Religious Conflict in Late Roman Syria. Berkeley Los Angeles London: University of California Press.

Segal, Erna (1956). Autobiographical Report, unpublished Manuscript (copy at the Gedenkstätte deutscher Widerstand Berlin). 
Seligmann, Avraham (1992). "An illegal way of life in Nazi Germany", in Grenville, John and Gross, Raphael (Ed.). Leo Baeck Institute Yearbook, no 37, Oxford: Oxford University Press, pp. 327-362.

Sémelin, Jacques and Andrieu, Claire and Gensburger, Sarah (2011). Resisting genocide. The multiple forms of rescue. Columbia University Press: New York.

Severy, Beth (2003). Augustus and the Family at the Birth of the Roman Republic, New York London: Routledge.

Stuber, Martin and Hächler, Stefan and Krempel, Lothar and Ruisinger, Marion Maria (2008). "Exploration von Netzwerken durch Visualisierung. Die Korrespondenznetze von Banks, Haller, Heister, Linné, Rousseau, Trew und der Oekonomischen Gesellschaft Bern", in Dauser, Regina and Hächler, Stefan and Kempe, Michael and Mauelshagen, Frank (Ed.). Wissen im Netz. Botanik und Pflanzentransfer in europäischen Korrespondenznetzen des 18. Jahrhunderts, Berlin: Akademie-Verlag, pp. 347-374.

Syme, Ronald (1974). "The Crisis of 2 B.C.", in Sitzungsberichte der Bayerischen Akademie der Wissenschaften, no 7, München: Verlag der Bayerischen Akademie der Wissenschaften.

Syme, Ronald (2003). Die Römische Revolution. Machtkämpfe im antiken Rom, Stuttgart: Klett-Cotta.

Tausendfreund, Doris (2005). Erzwungener Verrat: Jüdische "Greifer" im Dienst der Gestapo 1943 - 1945. (Dokumente, Texte, Materialien, $n^{\circ}$ 62) Berlin: Metropol Verlag.

Varese, Federico and Yaish, Meir (2000). "The Importance of being asked. The Rescue of Jews in Nazi Europe". Rationality and Society, no 12, pp. 307-334.

Wasserman, Stanley and Faust, Katherine (1994). Social Network Analysis. Methods and Applications, Cambridge: Cambridge University Press.

White, Douglas R. and Jorion, Paul (1992). "Representing and Computing Kinship: A New Approach". Current Anthropology, no 33, pp. 454-463.

Windolf, Paul (2007). "Sozialkapital und soziale Ungleichheit: Vergleichende Analysen zur Unternehmensverflechtung in Deutschland und in den USA (18961938)", in Jahrbuch für Wirtschaftsgeschichte, no 2, pp. 197-230. 


\section{Recursos de internet}

Exzellenzcluster "Gesellschaftliche Abhängigkeiten und soziale Netzwerke" of the Universities of Trier and Mainz at http://www.netzwerk-exzellenz.uni-trier.de (accessed 30. November 2011).

Gedenkstätte deutscher Widerstand at www.gdw-berlin.de (accessed 6. September 2011).

Historical Network Research at

https://sites.google.com/site/historicalnetworkresearch/ (accessed 8. November 2011).

Kronenwett, Michael and Schönhuth, Michael (2011). VennMaker 1.2. Manual available at http://www.vennmaker.com/dl/VennMaker 12 Manual.pdf (accessed 6. September 2011).

Ucinet, Tool for Network Computation available at http://www.analytictech.com/ucinet/ (accessed 6. September 2011).

Visone, Tool for Network Visualization available online at http://www.visone.info (accessed 6. September 2011).

Yad Vashem at www.yadvashem.org (accessed 6. September 2011). 